\title{
Descending projections to the dorsal and ventral divisions of the cochlear nucleus in guinea pig
}

\author{
Susan E. Shore ${ }^{1}$, Robert H. Helfert ${ }^{2}$, Sanford C. Bledsoe, Jr. ${ }^{2}$, Richard A. Altschuler ${ }^{2}$ \\ and Donald A. Godfrey ${ }^{1}$ \\ 'Department of Otolaryngology, Medical College of Ohio, Toledo, Ohio, and ${ }^{2}$ Kresge Hearing Research Institute, \\ University of Michigan, Ann Arbor, Michigan, U.S.A.
}

(Received 6 August 1990; accepted 17 October 1990)

\begin{abstract}
The origins of extrinsic projections to the guinea pig dorsal and ventral cochlear nuclei were identified by examining the retrograde transport of horseradish peroxidase conjugated to wheatgerm agglutinin following its injection into each of these divisions. Major projections originated in periolivary regions of the superior olivary complex, the contralateral cochlear nucleus and the inferior colliculus. There was no contribution from the nuclei of the lateral lemniscus to these pathways. The heaviest projection from the periolivary regions to both divisions of the cochlear nucleus arose bilaterally in the ventral nucleus of the trapezoid body. The ipsilateral lateral nucleus of the trapezoid body also projected heavily to dorsal and ventral cochlear nucleus. In addition, the ventral cochlear nucleus received a substantial projection from the dorsal aspect of the ipsilateral dorsomedial periolivary nucleus. Projections originating bilaterally in the central nucleus of the inferior colliculus terminated in the deep layers of dorsal cochlear nucleus. These projections appear to be more strongly ipsilateral and specific than those reported in the cat.
\end{abstract}

Horseradish peroxidase; Ventral cochlear nucleus; Dorsal cochlear nucleus; Superior olivary nuclei; Inferior colliculus

\section{Introduction}

Previous studies have shown that in addition to synaptic endings from the VIIIth nerve (for reviews see Cant and Morest, 1984; Caspary, 1986), most neurons in the cochlear nucleus receive innervation from non-cochlear sources (Cant, 1981; Kane and Finn, 1977; Kane and Conlee, 1979;

Abbreviations: AVCN = Anteroventral cochlear nucleus; $\mathrm{CN}=$ Cochlear nucleus; $\mathrm{CPO}=$ Caudal periolivary region; $\mathrm{DCN}=$ Dorsal cochlear nucleus; $\mathrm{DMPO}=$ Dorsomedial periolivary nucleus; $\mathrm{DPO}=$ Dorsal periolivary nucleus; $\mathrm{IC}=$ Inferior colliculus; LNTB = Lateral nucleus of the trapezoid body; LSO = Lateral superior olivary nucleus; $M N T B=$ Medial nucleus of the trapezoid body; MSO=Medial superior olivary nucleus; OCB = Olivocochlear bundle; PVCN = Posteroventral cochlear nucleus; $\quad S O C=$ Superior olivary complex; $V C N=$ Ventral cochlear nucleus; VNTB $=$ Ventral nucleus of the trapezoid body.

Correspondence to: S.E Shore, Medical College of Ohio, Department of Otolaryngology, Toledo, $\mathrm{OH} 43699$, U.S.A.
Rasmussen, 1960, 1967; Osen et al., 1984; Van Noort, 1969; Adams, 1983; Elverland, 1977). Many of the non-cochlear synaptic endings in the cochlear nucleus originate in neurons of the superior olivary complex, nuclei of the lateral lemniscus, the inferior colliculus, and the contralateral cochlear nucleus (Van Noort, 1969; Adams and Warr, 1976; Kane, 1977; Elverland, 1977; Cant and Gaston, 1982; Adams, 1983; Spangler et al., 1987; Covey et al., 1984; Winter et al., 1989; Benson and Potashner, 1990).

The manner in which periolivary cell groups and other auditory areas project to specific cochlear nucleus neuronal targets is critical to the ability of these neurons to process complex signals and operate over a wide dynamic range. This study addresses the question of interspecies differences in the organization of olivary projections to specific regions of the cochlear nucleus. The methodology differs from other studies in the guinea pig by examining and quantifying the ret- 
rograde transport of horseradish peroxidase conjugated to wheatgerm agglutinin from different regions of the cochlear nucleus to other brainstem nuclei. In the cat, these projections terminate in all regions of the cochlear nucleus, with some nucleotopic organization: The rostral periolivary regions project more heavily to rostral cochlear nucleus while the caudal periolivary groups project more heavily to caudal cochlear nucleus (Van Noort, 1969; Adams, 1983; Spangler et al., 1987). The tree shrew, on the other hand, shows a more specific distribution pattern, with the dorsomedial periolivary region and dorsal periolivary region projecting only to the anteroventral cochlear nucleus, whereas the ventral nucleus of the trapezoid body and the caudal portion of the lateral nucleus of the trapezoid body project only to dorsal cochlear nucleus and posteroventral cochlear nucleus (Covey et al., 1984). In contrast to the tree shrew, a recent study of the superior olivary projections to cochlear nucleus in the guinea pig showed similar results to those found in the cat (Winter et al., 1989). This was surprising in view of findings that brainstem projections to the cochlea in guinea pig and cat differ in their organization (Robertson, 1985; Robertson et al., 1987).

This study has confirmed reports that major projections to the cochlear nucleus originate in periolivary regions of the superior olivary complex, the contralateral cochlear nucleus (see Shore et al., 1991), and the inferior colliculus. The results here indicate that some periolivary nuclei in the guinea pig have more specific target areas in the cochlear nucleus than previously indicated. In particular, the projections from the dorsomedial periolivary regions in the guinea pig terminate primarily in the ventral division of the cochlear nucleus. The guinea pig also receives more strongly ipsilateral projections from periolivary nuclei to the cochlear nucleus, than the cat (e.g. Adams, 1983). These findings imply that information processing in the auditory brainstem may vary significantly among species.

\section{Methods}

Fifteen pigmented guinea pigs $(250-400 \mathrm{~g})$ were anesthetized with ketamine hydrochloride (Keta- set; $80 \mathrm{mg} / \mathrm{kg}$ ) and xylazine (Rompun; $4 \mathrm{mg} / \mathrm{kg}$ ) administered intramuscularly. Periodic supplementation was used to maintain anesthetic levels throughout the procedure. The left cochlear nucleus was visualized, after a posterior fossa surgical approach, by aspirating a small part of the overlying cerebellum. A glass micropipette filled with $2 \%$ wheat germ agglutinin conjugated to horseradish peroxidase (WGA-HRP), in phosphate buffered saline ( $\mathrm{pH} 7.4)$, was placed under visual control on the surface of the dorsal or ventral cochlear nucleus. After the electrode placement, the brain was covered with warm mineral oil to prevent tissue desiccation and reduce brain pulsation. Evoked potentials in response to click stimulation were recorded as the electrode was advanced ventrally (see Shore and Nuttall, 1985). At a depth corresponding to the maximum-amplitude evoked potential, a continuous, positive current $(3-5 \mu \mathrm{A})$ was passed through the silver recording wire for 2-15 min. After the electrode was removed, some neck muscle was applied to replace the volume of aspirated brain, dental cement was used to seal the opening, and the animal was sutured and allowed to recover. After a 24-h survival period, the animal was deeply anesthetized with pentobarbital and perfused transcardially with $50 \mathrm{ml}$ of $0.05 \%$ sodium nitrite in normal saline, followed by $750 \mathrm{ml}$ of mixed aldehyde fixative $(1.25 \%$ glutaraldehyde and $1.0 \%$ formaldehyde in phosphate buffer, $\mathrm{pH}$ 7.4). Following their removal from the skull and postfixation for $2-4 \mathrm{~h}$ in the same fixative, the brainstems were immersed overnight in $20 \%$ sucrose in $0.12 \mathrm{M}$ phosphate buffer, $\mathrm{pH}$ 7.4. After frozen sectioning, the $40 \mu \mathrm{m}$-thick transverse sections containing the cochlear nucleus (CN), superior olivary complex (SOC), nuclei of the lateral lemniscus (NLL) and IC were reacted with $3,3^{\prime}-5,5^{\prime}$-tetramethylbenzidine (TMB) to visualize the peroxidase (Mesulam, 1978). The reacted sections were then mounted, counterstained with neutral red (Mesulam, 1978) and studied using a Leitz Dialux microscope equipped with a drawing tube. An estimate of the total number of labeled cells in the SOC was obtained by counting those in every 5 th section. Labeled cell types were described in terms of soma shape and size, and the location of the nucleus when possible. Soma size was measured 
using a calibrated eyepiece micrometer. The measurements presented are not corrected for tissue shrinkage which occurs during processing.

\section{Results}

Injections in the cochlear nucleus produced retrograde labeling in the ipsilateral and contralateral cochlear nucleus, supcrior olivary complex (SOC) and inferior colliculus. Only the projections from the SOC and inferior colliculus are discussed in this paper; the cochlear nucleus projections are presented elsewhere (Shore et al.,
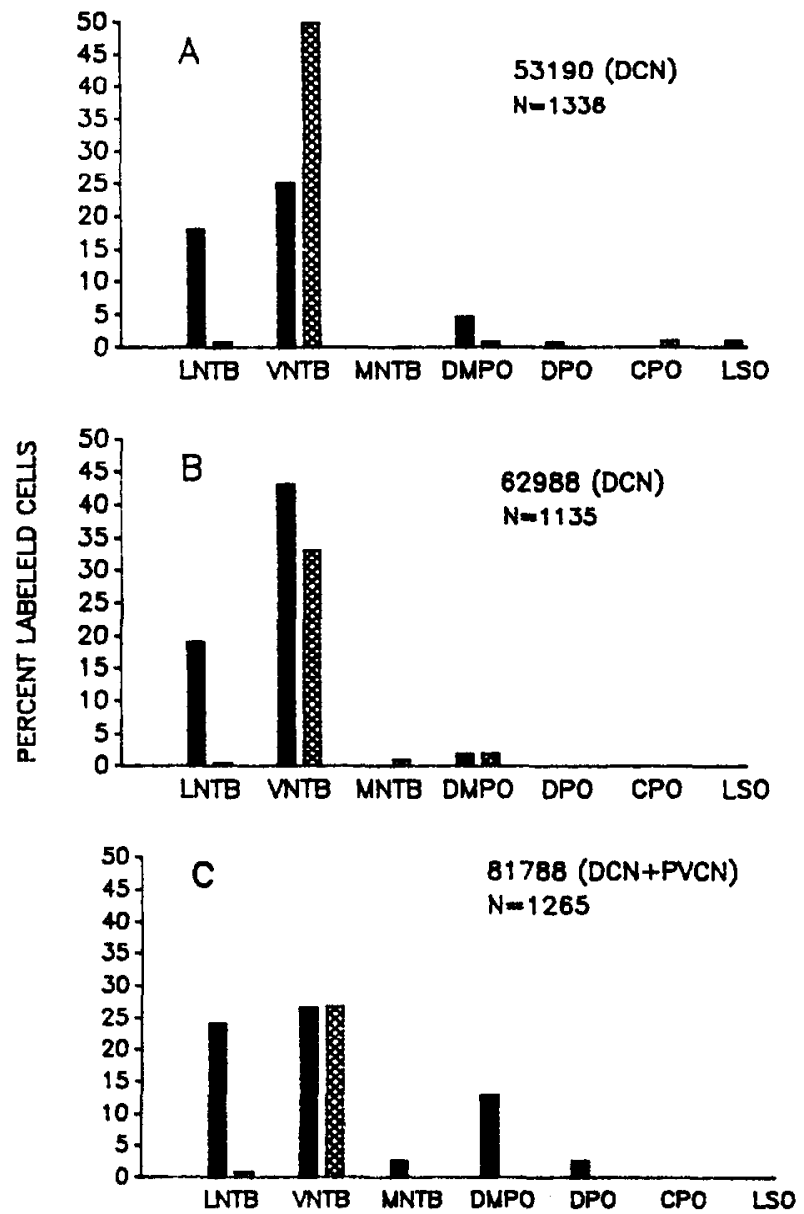

SUPERIOR OLIVARY REGION
1991). There was a different distribution of labeled cells in each of these major regions, depending on whether the injection was centered in dorsal cochlear nucleus (DCN) or ventral cochlear nucleus.

Descending projections from the superior olivary complex

\section{Definition of periolivary regions}

Periolivary nuclei are defined in terms of their positions with respect to the lateral and medial
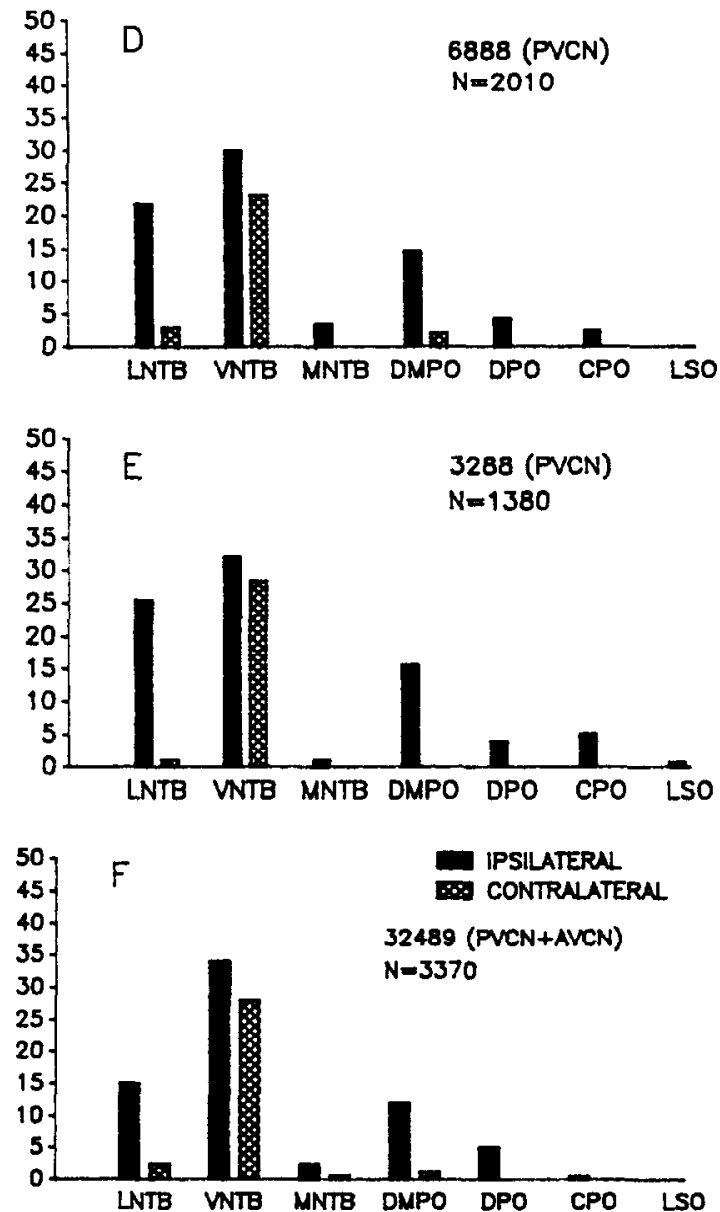

\section{SUPERIOR OLNARY REGION}

Fig. 1. Percentages of labeled cells in different SOC nuclei following WGA-HRP injections centered on different cochlear nucleus regions, as indicated in parentheses. (A) Animal 53190; injection centered on medial DCN. (B) Animal 62988; injection centered on DCN. (C) Animal 81788; injection centered on DCN and PVCN. (D) Animal 6888; injection centered on PVCN. (E) Animal 3288; injection centered on PVCN. (F) Animal 32489; injection centered on PVCN and AVCN. 

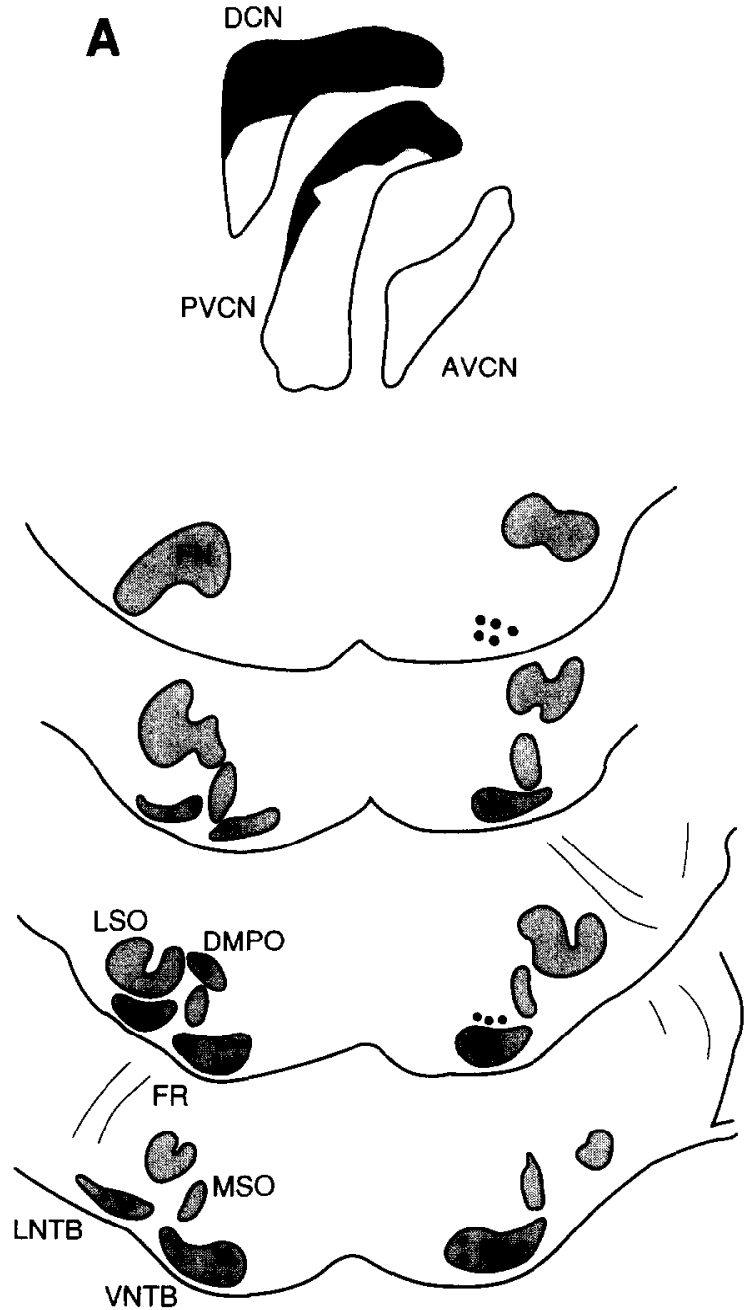

B
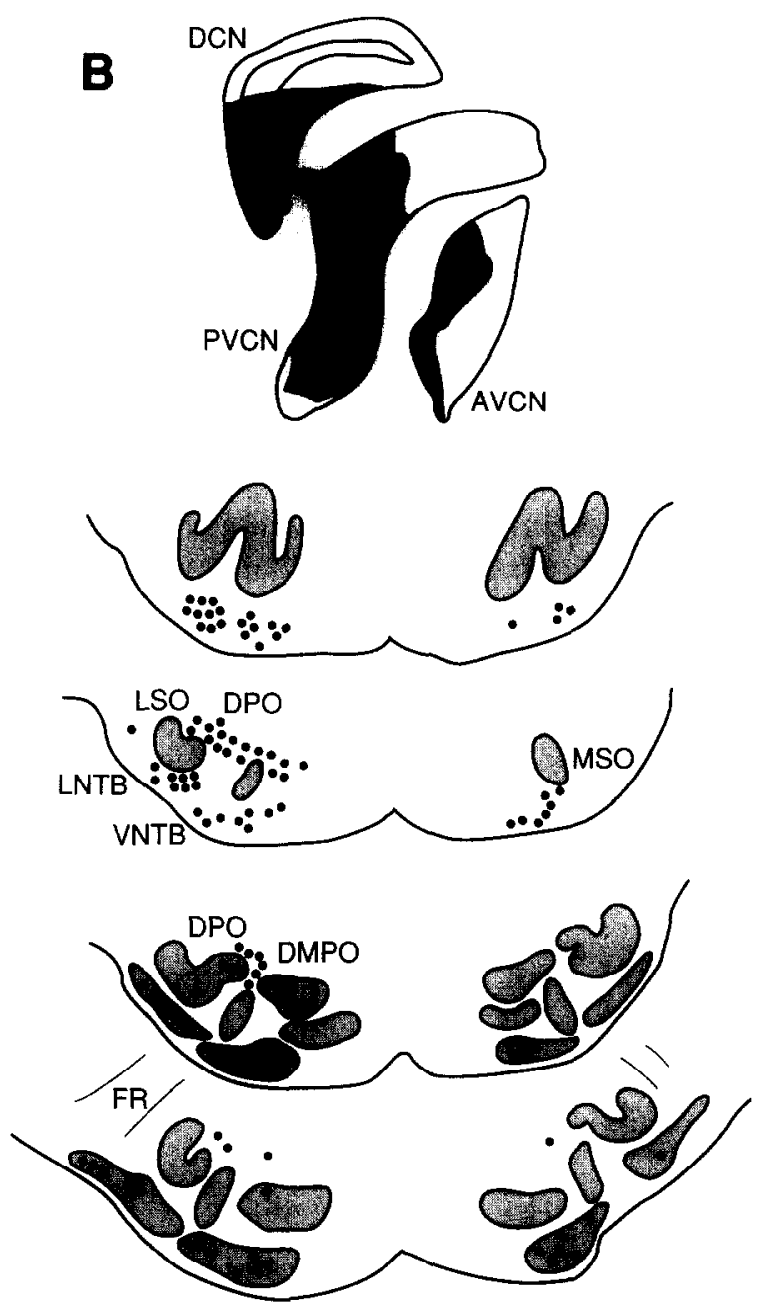

Fig. 2. Camera lucida reconstructions of $40 \mu \mathrm{m}$ transverse sections of the brainstem showing labeled cells after a WGA-HRP injection into DCN (animal No. 62988, left panel) and PVCN (animal 70688, right panel). Each dot represents one labeled cell.

superior olivary nuclei (LSO and MSO; modified after Morest, 1968; Osen, 1969):

The ventral nucleus of the trapezoid body (VNTB) is defined as the group of cells ventral to the medial nucleus of the trapezoid body (MNTB) and ventromedial to the MSO. The lateral nucleus of the trapezoid body (LNTB) includes cells ventral to the LSO and ventrolateral to the MSO. The dorsomedial periolivary nucleus (DMPO) includes those cells dorsal to the MSO and MNTB, with its lateral boundary drawn as a tangent to the medial limb of the LSO, parallel to the long axis of the MSO. The DMPO has also been referred to as the superior paraolivary nucleus (SPN). The dorsal periolivary region (DPO) includes those cells dorsal to the LSO and dorso-lateral to the DMPO. The caudal periolivary region (CPO) denotes the cell group with the same boundaries as the DPO, but located caudal to the LSO.

Distribution of labeled cells in brainstem nuclei as a function of injection site

The distribution of labeled cells in the SOC was dependent on the location of the WGA-HRP injection. This can be seen in Fig. 1, which shows the percentages of retrogradely labeled cells in regions of the SOC following injections into different regions of the CN. (Percentage is based on 
the total number of labeled cells counted in the SOC). These percentages were consistent for a given injection site despite variations in the total number of labeled cells ( $N$, shown above each histogram) found in each animal.

\section{Distribution of labeled cells after dorsal cochlear nucleus injections}

Injections centered on DCN produced numerous labeled neurons in the ipsilateral and contralateral VCN (described in separate papers), VNTB bilaterally and the LNTB ipsilaterally, with few labeled neurons in the remaining SOC nuclei (Fig. 1A, B). If PVCN was included in the injection site, a substantial number of cells was labeled in the ipsilateral DMPO (as in animal 81788, Fig. 1C). Fig. $2 \mathrm{~A}$ shows a camera lucida reconstruction of the positions of labeled cells after a large HRP injection encompassing the entire rostro-caudal and medio-lateral extent of the DCN. The percentages of labeled SOC neurons in the same animal are shown in Fig. 1B. Labeled cells were seen predominantly in the ipsilateral LNTB (19\%) and VNTB (43\%), and the contralateral VNTB (33\%). A few labeled cells were seen in the ipsilateral DMPO, but these comprised fewer than $2 \%$ of the total number of labeled cells in the SOC. Sixty four percent of the projection was ipsilateral. An injection encompassing a smaller and more medially located portion of the $\mathrm{DCN}$ produced similar percentages of labeled cells in each region of the SOC, except that the contralateral VNTB showed higher counts (Fig. 1A). Both DCN injections produced higher percentages of labeled cells in the contralateral VNTB than any of the VCN injections. The predominantly ipsilateral labeling in the IC was seen only in animals in which the deep layers of the $D C N$ were included in the injection site. After small injections into the granular and molecular layers of $\mathrm{DCN}$, little labeling was observed, except in the granular layer dorsolateral to the AVCN.

Distribution of labeled cells after ventral cochlear nucleus injections

Injections encompassing both $\mathrm{PVCN}$ and AVCN (Figs. 1D-F and 2B) resulted in major retrograde labeling of cells in the ipsilateral LNTB and DMPO and bilaterally in the VNTB. Ad- ditional labeled neurons were located in the ipsilateral DPO, CPO, MNTB and occasionally LSO. Percentages of cells seen in the ipsilateral LNTB were highest for centrally-placed injections including most of PVCN and only the caudal portions of AVCN (Figs. 1D, and E). These percentages were lower in cases where the injections were either in the caudal PVCN (Figs. 1A and B) or rostral AVCN (Fig. 1E) portions of the cochlear nucleus. The total ipsilateral contribution for animals with predominantly VCN injections was higher than for a predominantly $\mathrm{DCN}$ injection $(69-72 \%$ vs 47-64\%).

In one animal (81788, Fig. $1 \mathrm{C})$, the absence of HRP in the ventral PVCN correlated with a decreased number of labeled cells in the ipsilateral VNTB and CPO, compared to those animals in which ventral PVCN was included in the injection site. This may suggest a projection from the caudal periolivary region to ventral PVCN.

The pattern of retrograde labeling in different regions of the SOC

Ventral nucleus of the trapezoid body (VNTB)

The VNTB always contained the highest percentage $(50-80 \%)$ of labeled cells in the SOC, regardless of the injection site. The percentage was higher on the contralateral side for $\mathrm{DCN}$ injections compared to $\mathrm{VCN}$ injections. The preponderance of labeled cells in the contralateral SOC was in the VNTB $(>90 \%)$ for all injections.

Examples of the range of relative sizes and shapes of labeled cells in the VNTB are shown in Fig. 3. The distribution of labeled cells within the VNTB differed depending on whether the injection was ipsi- or contralateral. Labeled cells were found across the entire medial-to-lateral extent of the ipsilateral VNTB (Fig. 3), but tended to form clusters toward the medial aspect of the contralateral VNTB. Cell types seen on both sides were similar and included oval, fusiform and polygonal cell bodies ranging from $10-40 \mu \mathrm{m}$ in length (Fig. 3). A preponderance of the smaller cells was located in the medial portion of the VNTB on both sides. Nuclei, when seen, were often concentric within the somata. The larger, polygonal neurons were typically found toward the lateral aspect of the VNTB. The long axes of 


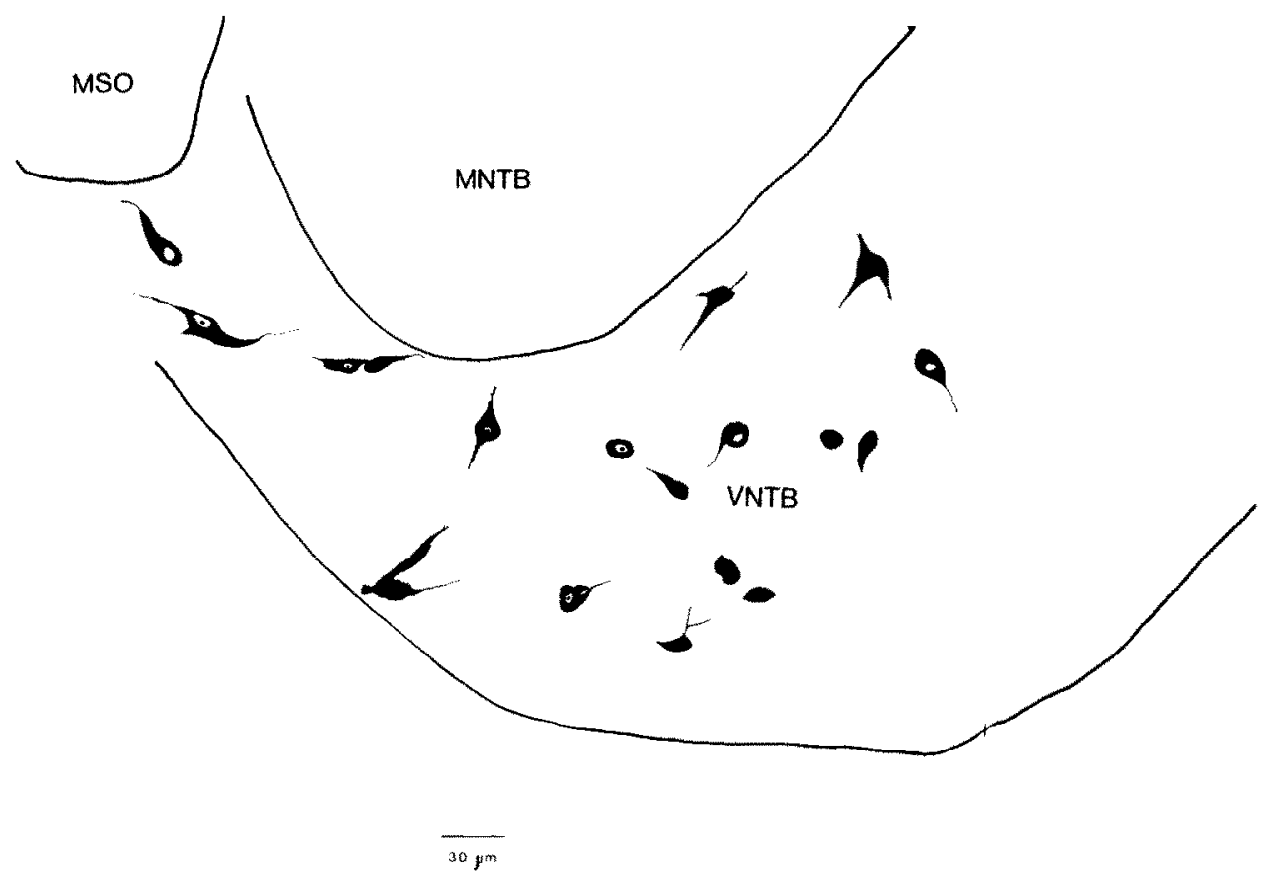

Fig. 3. Camera lucida drawings of labeled cells in a transverse $40 \mu \mathrm{m}$ section of the the VNTB ipsilateral to the HRP injection.

these and the fusiform cells were usually oriented parallel to fibers of the trapezoid body. There were less labeled neurons in the lateral portions of the contralateral VNTB, and the proportion of labeled small cells was more marked there than on the ipsilateral side.

\section{Lateral nucleus of the trapezoid body (LNTB)}

Between 15 and $25 \%$ of labeled cells were always seen in the ipsilateral LNTB. Fewer than $3 \%$ of the labeled cells were found in the contralateral LNTB, regardless of the injection site. Labeling was found along the entire medial-lateral extent of the LNTB. Examples of the ranges of shapes and sizes of labeled LNTB neurons are shown in Fig. 4. Labeled cells had fusiform, polygonal and oval cell bodies ranging in size from 15 to $50 \mu \mathrm{m}$ in length. As with the elongated cells in the VNTB, the long axes of these cells were oriented parallel to fibers of the trapezoid body.

\section{Dorsal periolivary regions}

As many as $16 \%$ of labeled cells were found in the ipsilateral DMPO after VCN injections, whereas fewer than $5 \%$ of labeled cells were observed in this region after an injection restricted to the DCN. The contralateral DMPO contained less than $1 \%$ of the labeled cells for VCN injections and less than $2 \%$ for DCN injections. Examples of the range of shapes and sizes of labeled cells in this region are shown in Fig. 5. Oval, fusiform and polygonal cell bodies, ranging from 12 to $42 \mu \mathrm{m}$ in length, were labeled in this region. Nuclei were both concentrically and eccentrically located within the somata.

The DPO ipsilateral to $\mathrm{VCN}$ injections contained up to $6 \%$ of labeled cells. Cells were predominantly larger fusiform and smaller oval (see Fig. 5). Significant labeling was seen in CPO only after injections into caudal ventral cochlear nucleus. Soma shapes and sizes were similar to those seen in the DPO and DMPO. The orientation of dendrites in DPO and DMPO may be of significance in distinguishing between the two groups of neurons. There is a tendency for dendrites of cells in the DPO to be oriented parallel to the dorsal curvature of the LSO, and those in the DMPO to be oriented perpendicular to the 


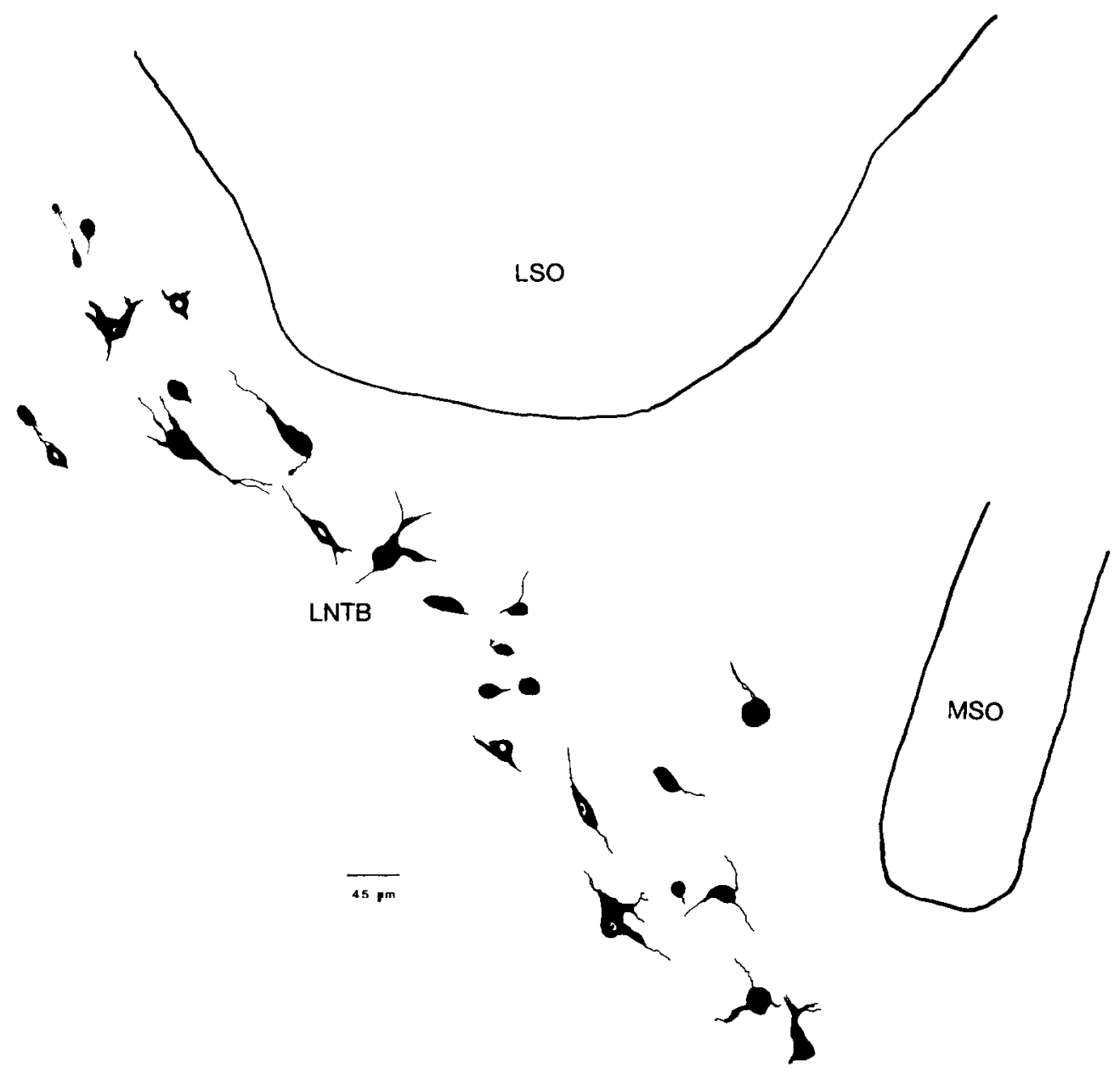

Fig. 4. Camera lucida drawings of labeled cells in a transverse $40 \mu \mathrm{m}$ section of the LNTB ipsilateral to the HRP injection.

medial curvature of the LSO surface (Fig. 5). Further study using Golgi staining is necessary to confirm this suggestion.

Medial nucleus of the trapezoid body (MNTB)

A small percentage $(<4 \%)$ of backlabeled cells was observed in the ipsilateral MNTB after VCN injections, but not $\mathrm{DCN}$ injections. Anterograde labeling was routinely seen in the contralateral MNTB with any large injection into VCN. Labeled somata and those receiving labeled terminals both had large ( $30 \mu \mathrm{m}$ in length), oval somata.

\section{Other regions}

Backlabeled cells $(<2 \%)$ with small round $(12$ $\mu \mathrm{m})$ somata were observed within the neuropil of the lateral limb of the ipsilateral LSO in some animals (e.g. 53190 and 3288). No labeled cells were seen in the contralateral LSO with any injection. In some animals, a few labeled cells were seen bilaterally in the nucleus of the spinal trigeminal tract and near the facial nucleus on the side ipsilateral to the injection.

\section{Descending projections from the inferior colliculus}

Fig. 6 shows the location of labeled cells in the central nucleus of the inferior colliculus following injections into the DCN. Two different animals are shown. Labeled cells were seen only when the deep layers of the DCN were included in the injection site. More cells were seen with lateral 


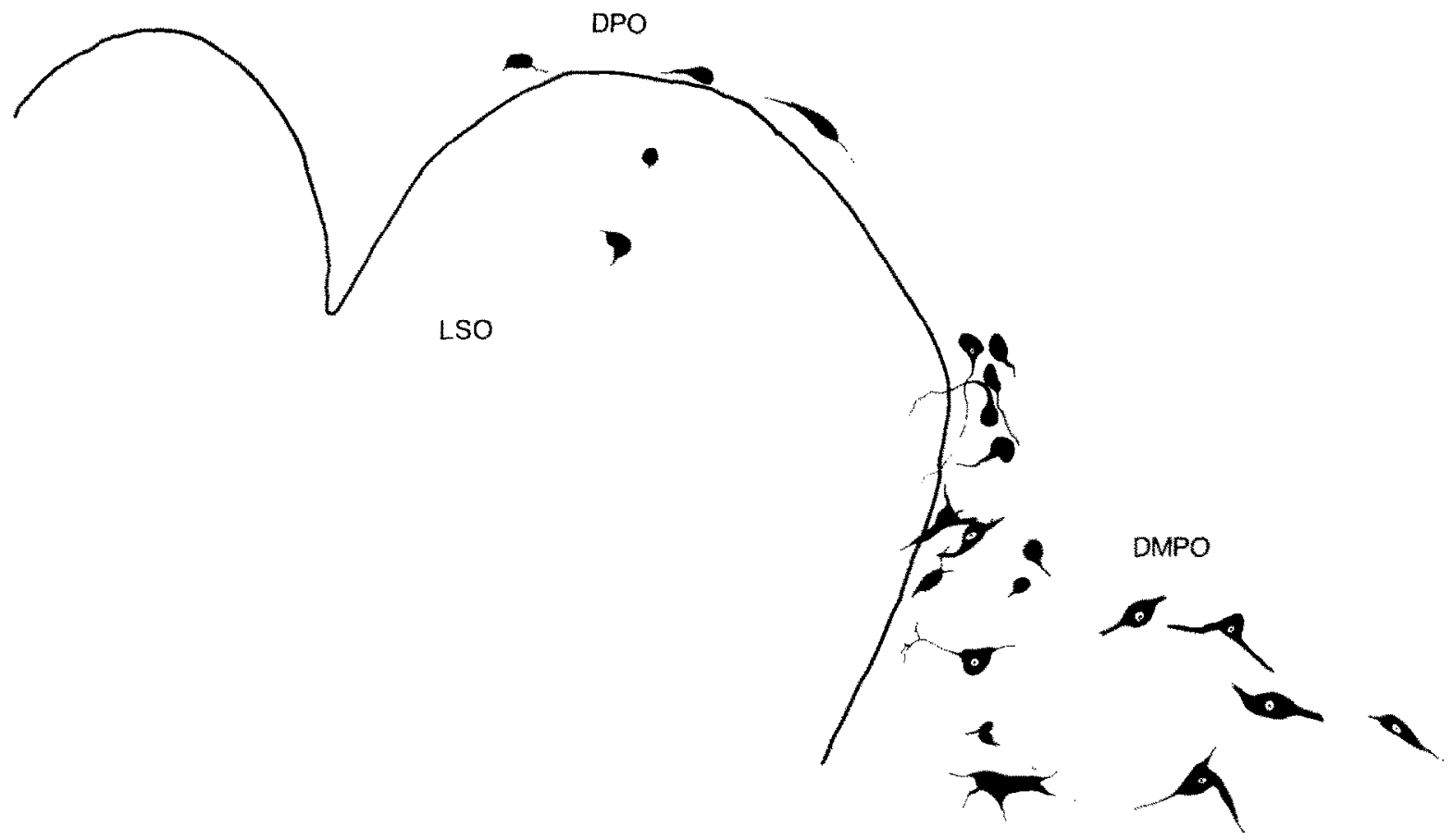

$\overline{42, y+m}$

\&

Fig. 5. Camera lucida drawings of labeled cells in a $40 \mu \mathrm{m}$ transverse section of the DPO and DMPO ipsilateral to the HRP injection.
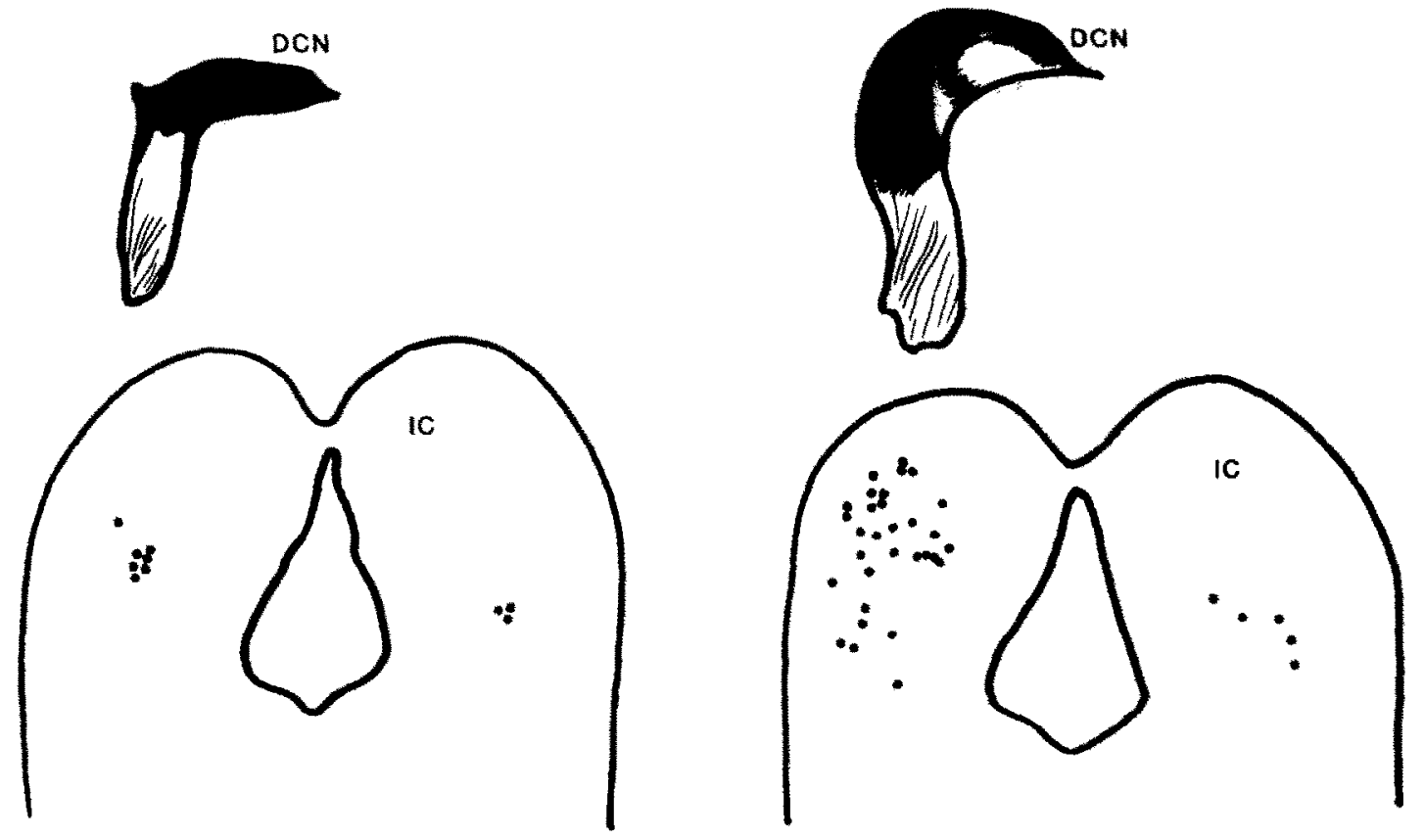

Fig. 6. Camera lucida drawing of $40 \mu \mathrm{m}$ transverse sections of the IC showing labeled cells in the central region on both sides following WGA-HRP injections into the DCN of two different animals (animal Nos. 62988, left; and 81788, right). 


\section{INFERIOR COLLICULUS}

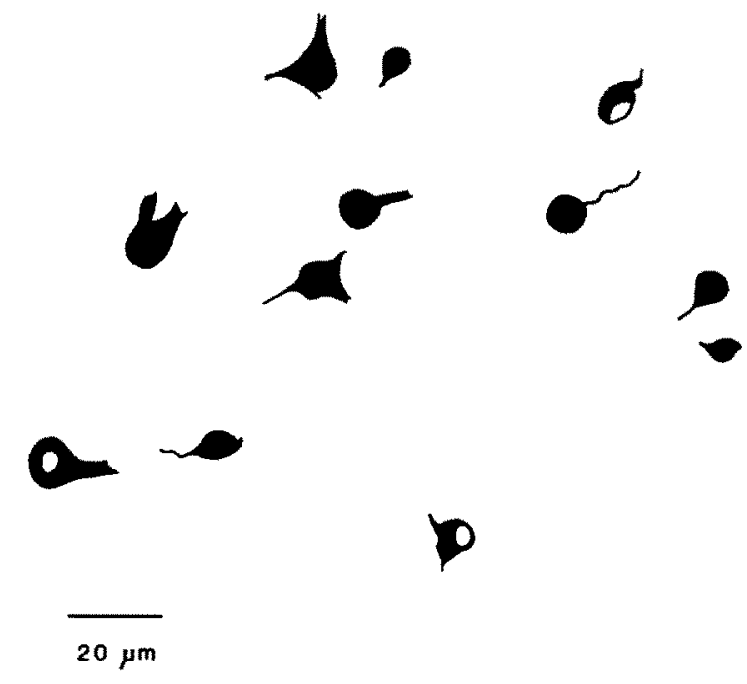

Fig. 7. Camera lucida drawings of labeled cells in a $40 \mu \mathrm{m}$ transverse section of the central nucleus of the IC following injections into the ipsilateral DCN.

(Fig. 6, right) than with medial (Fig. 6, left) injections. Small injections into the $\mathrm{DCN}$ which included only the molecular and part of the granular layer produced no labeled cells in the $\mathrm{IC}$, nor did a small injection into the medial portion of the DCN, even though it included layers 3 and 4 .

Backlabeleld cells in the IC all had mediumsized $(15-20 \mu \mathrm{m})$ round or oval somata, with only one or two dendrites visible. Nuclei, when visible, were either concentrically or eccentrically located within their somata (Fig. 7).

\section{Discussion}

The results of this study agree with previous studies in the guinea pig and those from other species that major projections to the cochlear nucleus arise in periolivary regions of the superior olivary complex and project topographically to all divisions of the cochlear nucleus (Fig. 8) (Adams and Warr, 1976; Adams, 1983; Covey et al., 1984; Spangler et al, 1987; Zook, 1985; Winter et al., 1989; Benson and Potashner, 1990). This study differs from previous studies by demonstrating, as

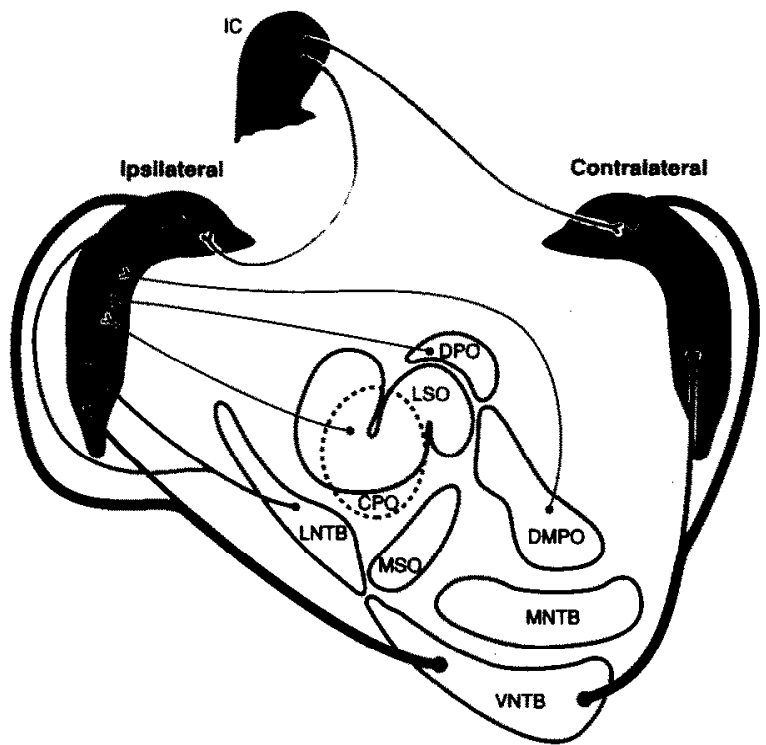

Fig. 8. Schematic representation of the superior olivary complex and inferior colliculus projections to the cochlear nucleus, as determined using injections of WGA-HRP into the cochlear nucleus. Exact axonal trajectories are not indicated. Black lines denote quantified pathways. Grey lines denote unquantified pathways. Line thickness indicates the relative size of the pathway. 
in the tree shrew (Covey et al., 1984), that some of the periolivary projections to the cochlear nucleus in the guinea pig are more specific than those shown for the cat. In the present study, the distribution of labeled cells was dependent on the location of the injection site. When the injection site was centered on dorsal cochlear nucleus, far fewer labeled cells were seen in the dorsal periolivary regions, as compared to ventral cochlear nucleus, and more labeled cells were seen in the ventral nucleus of the trapezoid body, especially on the contralateral side.

This study also demonstrates species-specific differences in the laterality of projections among the periolivary nuclei. Projections originating in the dorsomedial and ventrolateral periolivary regions were more strongly ipsilateral in the guinea pig than those shown in either the cat or the tree shrew (Spangler et al., 1987; Covey et al., 1984). Dorsomedial periolivary projections to the ventral cochlear nucleus and ventrolateral projections to the dorsal and ventral cochlear nucleus were almost entirely ipsilateral, whereas ventromedial projections to dorsal and ventral cochlear nucleus were more equally bilateral. The same degree of ipsilateral predominance was not reported by Benson and Potashner (1990) who made very large injections of HRP combined with WGA-HRP into the entire cochlear nucleus. The presence of more retrograde label in contralateral periolivary nuclei may be a reflection of the much larger size of their injections in the cochlear nucleus and diffusion into adjacent brainstem structures, as well as the use of HRP in addition to WGA-HRP. The ipsilateral predominance of the dorsomedial periolivary projection to the cochlear nucleus shown in this study was also demonstrated by Winter et al. (1989). That study did not, however, show a difference in the distribution of input to the ventral and dorsal divisions ; they obtained labeled cells in the dorsal periolivary regions with both dorsal and anteroventral cochlear nucleus injections. Either their dye injections into dorsal cochlear nucleus may have included unrecognized spread to ventral cochlear nucleus, or the terminals of cells in the dorsal periolivary regions projecting to dorsal cochlear nucleus may not readily take up WGA-HRP. It is not possible to compare the laterality of the ventral periolivary pathways be- tween the two studies since those authors did not make a distinction between the lateral and ventral nucleus of the trapezoid body, one which we considered important in view of the significant differential distribution of labeled cells in these two regions: the projection from the lateral nucleus of the trapezoid body is primarily ipsilateral, while that from the ventral nucleus of the trapezoid body is bilateral.

Winter et al. (1989) also saw more labeling in the lateral superior olive than found in the present study or in that of Bensen and Potashner (1990). Again, this difference could relate to differences in the exact injection sites, since they found lateral superior olive labeling especially with their rostral ventral cochlear nucleus injections, which extended farther rostral than those of the present study. Alternatively, as mentioned above, the fluorescent dyes used in their study may be taken up by thin fibers more extensively than WGA-HRP. Thus, a wider distribution of labeled neurons in the olivary nuclei may have occurred in their study, in line with the larger number of labeled cells reported. A difference which is difficult to explain on the basis of rostro-caudal injection locations, or tracer differences, is the reported presence of retrograde labeling in the ventral nucleus of the lateral lemniscus, which was entirely absent in the present study (Winter et al., 1989, Bensen and Potashner, 1990).

\section{Descending projections of olivocochlear collaterals to the cochlear nucleus}

The limited number of retrogradely labeled neurons observed in the LSO in this study is consistent with the findings of some investigators that few collaterals branch from the lateral olivocochlear system to the cochlear nucleus in guinea pig (Brown et al., 1988; Winter et al., 1989). However, Ryan et al. (1987), using retrograde uptake of D-aspartate, showed a substantial collateral projection from the lateral olivocochlear system to the cochlear nucleus in the gerbil. This might reflect a true species difference. Chemical measurements have suggested species differences between rat and cat, in the relatve contribution of olivocochlear collaterals to cholinergic innervation of the cochlear nucleus (Godfrey et al., 1987). 
Descending projections from the inferior colliculus

This study confirms findings in other species that the inferior colliculus projects to the cochlear nucleus (Rasmussen, 1955; Van Noort, 1969; Adams, 1976; Hashikawa 1983; Zook, 1985; Faye-Lund, 1986). Faye-Lund showed bilateral labeling of the central and external layer 3 of the inferior colliculus after a WGA-HRP injection centered on dorsal cochlear nucleus, but including some of posteroventral cochlear nucleus. In the present study, only injections encompassing the central layers of the dorsal cochlear nucleus resulted in labeling of cells in the inferior colliculus. When only the granular and part of the molecular layer were marked, no retrograde uptake occurred in the inferior colliculus. These findings are consistent with a conclusion that the major descending projections to the cochlear nucleus from the inferior colliculus of the guinea pig originate bilaterally in its central nucleus and terminate in the central layers of the dorsal cochlear nucleus.

\section{Extra-auditory projections from the brainstem to the} cochlear nucleus

The presence of labeled neurons in the ipsilateral (predominantly) spinal division of the trigeminal nucleus is consistent with findings in other species that some neurons in this nucleus send fibers to the dorsal and ventral cochlear nuclei (Itoh et al., 1987). A few labeled neurons were also observed in the region of the motor nucleus of the ipsilateral facial nerve. Such cells might be motor neurons of the stapedius muscle as described by Joseph et al. (1985) in the cat.

\section{Functional implications}

The manner in which descending projections innervate the cochlear nucleus must critically influence the way in which incoming VIIIth nerve information is processed. The exact function of the described extrinsic inputs to the cochlear nucleus is as yet unresolved. The synapses of these descending pathways employ a variety of neurotransmitters, including norepinephrine, acetylcholine, gamma-aminobutyric acid (GABA) and glycine (reviewed in Godfrey et al., 1988). Some of the synapses within the cochlear nucleus contain spherical vesicles, while others contain pleomorphic vesicles and appear to be rich in GABA and glycine, both putative inhibitory neurotransmitters (Cant and Morest, 1979; Adams and Mugnaini, 1985; Altschuler et al., 1986; Wenthold et al., 1986, 1987; Juiz et al., 1989). Benson and Potashner (1990) have demonstrated that glycine, when employed as a retrograde tracer, was taken up by all ipsilateral periolivary nuclei. This suggests that at least some of the descending projections which originate in periolivary nuclei and terminate in the cochlear nucleus are inhibitory.

Physiological evidence of inhibition within the cochlear nucleus includes the demonstration of inhibitory sidebands, non-linear input-output functions and the existence of IPSPs during intracellular recordings of sound-evoked responses (Evans and Nelson, 1973; Kiang et al, 1973; Godfrey et al., 1975; Brownell, 1975; Young and Brownell, 1976; Oertel, 1983; Young and Voight, 1981). Long-latency inhibition has also been observed in response to electrical stimulation of descending pathways to the cochlear nucleus (Starr and Wernick, 1968; Bourk, 1976). Bourk (1976) was able to elicit both gross- and single-unit responses in the ventral and dorsal cochlear nucleus following stimulation of the trapezoid body and inferior colliculus, respectively. He showed that single units in the cochlear nucleus could be excited and/or inhibited depending on the unit type. A suppression of tone-evoked activity occurred in some 'onset' units in the posteroventral cochlear nucleus following trapezoid body stimulation. Other units in the ventral cochlear nucleus, for example those of 'composite-type', also showed decreases in tone-evoked responses.

Electrical stimulation of the olivocochlear bundle and iontophoretic application of its neurotransmitter, acetylcholine, also elicit both inhibitory and excitatory responses in cochlear nucleus cells (Starr and Wernick, 1968; Comis and Whitfield, 1968; Comis and Davies, 1969; Brown and Buchwald; 1976; Caspary, 1986). Some studies have suggested that the descending pathways in general may facilitate recovery from adaptation and that input from cholinergic axons, in particular, may lower some neurons' thresholds (Comis 
and Whitfield, 1968; Comis and Davies, 1969; Comis, 1970; Brown and Buchwald, 1976).

Reports of both excitatory and inhibitory responses in ventral cochlear nucleus neurons with trapezoid body and olivocochlear bundle stimulation may be explained by the receptor types on different cells. Alternatively, different multiple pathways could have been stimulated in the different studies, depending on the electrode location. The proximity of the GABAergic, glycinergic, and cholinergic cells in the SOC (Helfert et al.. 1989; Adams, 1989) would make it difficult to electrically stimulate one system independently of the others. This study suggests that differences in processing may also exist among different species, but more selective methods of stimulation must be used to determine the stimulus paradigms needed to enable separate cell groups to be individually activated. In particular, it would be important to stimulate separately those cell groups which we have shown to have specific projections to certain portions of the cochlear nucleus. The dorsomedial periolivary region, which we have found to project primarily to the ventral cochlear nucleus, and the contralateral ventral nucleus of the trapezoid body, which projects more strongly to medial dorsal cochlear nucleus, are examples of these regions.

It has been suggested that one of the functions of the efferent system to the cochlea is to increase the dynamic range of the response of the peripheral auditory system (Winslow and Sachs, 1984). There is some evidence to suggest that descending inputs to the cochlear nucleus may participate in the processing of incoming afferent information in a similar way. Cochlear nucleus cells in general have wider operating ranges than VIIIth nerve fibers, especially for complex signals such as amplitude modulated sinusoids (Smith and Brachman, 1980; Frisina, 1983). Those units in the ventral cochlear nucleus whose responses to pure tones are most dissimilar to those of VIIIth nerve fibers have the widest operating ranges. Thus, it appears that those cells in which there is more processing of the incoming afferent information are specialized to encode complex signals more effectively over a wider range of intensities. The descending system described here may play a major role in this important aspect of information processing.

\section{References}

Adams, J.C. (1983) Cytology of periolovary cells and the organization of their projections in the cat. J. Comp. Neurol. 215, 275-289.

Adams, J.C. (1989) Non-olivocochlear cholinergic periolivary cells. Soc. Neurosci. Abstr. 15, 1114.

Adams, J.C. and Mugnaini E. (1985) Patterns of immunostaining with antisera to peptides in the auditory brainstem of cat. Soc. Neurosci. Abstr. 11, 32.

Adams, J.C. and Warr W.B. (1976) Origins of axons in the cat's acoustic striae determined by injection of horseradish peroxidase into severed tracts. J. Comp. Neurol. 170, 107122.

Altschuler, R.A., Betz, H. Parakkal, M.H. Reeks K.A. and Wenthold, R.J. (1986) Identification of glycinergic synapses in the cochlear nucleus through immunocytochemical localization of the postsynaptic receptor. Brain Res. 369. $316-320$.

Bensen, C.G. and Potashner, S.J. (1990) Retrograde transport of [3H] glycine from the cochlear nucleus to the superior olive in the guinea pig. J. Comp. Neurol. 296, 415-426.

Borg (1973) A neuroanatomical study of the brainstem auditory system of the rabbit -11: Descending connections. Acta Morphol. Neerl. Scand. 11, 49-62.

Bourk, T.R. (1976) Electrical responses of neural units in the anteroventral cochlear nucleus of the cat. Doctoral Dissertation, M.I.T, Cambridge, MA.

Brown, K.A. and Buchwald, J.S.(1976) Response decrements during repetitive tone stimulation in the surgically isolated cochlear nucleus. Exp Neurol. 53, 663-669.

Brown, M.C., Liberman, M.C. and Ryugo, D.K. (1988) Brainstem branches from olivocochlear axons in cats and rodents. J. Comp. Neurol. 278, 591-603.

Brownell, W.E. (1975) Organization of the cat trapezoid body and the discharge characteristics of its fibers. Brain Res. 94, $413-433$.

Cant, N.B. and Gaston, K.C. (1982) Pathways connecting the right and left cochlear nuclei. J. Comp. Neurol. 212, 313326.

Cant, N.B. and Morest, D.K. (1978) Axons from non-cochlear sources in the anteroventral cochlear nucleus of the cat. A study with the rapid Golgi method. Neuroscience 3, 10031029 .

Cant, N.B. and Morest D.K. (1979) The bushy cells in the anteroventral cochlear nucleus of the cat. A study with the electron mciroscopoe. Neuroscience 4, 1925-1945.

Cant, N.B. and Morest, D.K. (1984) The Structural Basis for Stimulus Coding in the Cochlear Nucleus of the Cat. In: C.I. Berlin (Ed.), Hearing Science. College Hill Press, San Diego, pp. $371-421$.

Caspary, D.M. (1986) Cochlear Nuclei: Functional Neuropharmacology of Principal Cell Types. In: R.A. Altschuler, R.P. Bobbin and D.W. Hoffman (Eds.), Neurobiology of Hearing: The Cochlea. Raven Press. New York, pp. 303332.

Comis, S.D. (1970) Centrifugal inhibitory processes affecting neurones in the cat cochlear nucleus. J. Physiol. (Lond) 210 , $751-760$. 
Comis, S.D. and Daves, W.E. (1969) Acetylcholine as a transmitter in the cat auditory system. J. Neurochem. 16, 423429.

Comis, S.D. and Whitfield, I.C. (1968) Influence of centrifugal pathways on unit activity in the cochlear nucleus. $J$. Neurophysiol. 31, 62-68.

Covey, E., Jones, D.R. and Casseday, J.H. (1984) Projections from the superior olivary complex to the cochlear nucleus in the tree shrew. J. Comp. Neurol. 226, 289-305.

Elverland, H.H. (1977) Descending connections between the superior olivary and cochlear nuclear complexes in the cat studied by autoradiographic and horseradish peroxidase methods. Exp. Brain Res. 27, 389-412.

Evans, E.F. and Nelson, P.G. (1973) On the functional relationship between the dorsal and ventral divisions of the cochlear nucleus of the cat. Exp Brain Res 17, 428-442.

Faye-Lund, H. (1986) Projection from the inferior colliculus to the superior olivary complex in the albino rat. Anat. Embryol. 175, 35-52.

Frisina, R. (1983) Enhancement of responses to amplitude modulation in gerbil cochlear nucleus: single-unit recordings using an improved surgical approach. Special Report IRS-s-23, Institute for Sensory Research, Syracuse, NY.

Godfrey, D.A., Kiang, N.Y.S. and Norris, B.E. (1975) Single unit activity in the posteroventral cochlear nucleus of the cat. J. Comp. Neurol. 162, 247-268.

Godfrey, D.A., Park-Hellendall, J.L., Dunn, J.D. and Ross, C.D. (1987) Effect of olivocochlear bundle transection. Hear. Res. 28, 237-252.

Godfrey, D.A., Parli, J.A., Dunn, J.D. and Ross, C.D. (1988) Neurotransmitter microchemistry of the cochlear nucleus and superior olivary complex. Auditory Pathway. Syka, J, and R.B. Masterton (eds). New York: Plenum. pp 107-121.

Hashikawa, T. (1983) The inferior colliculopontine neurons of the cat in relation to other collicular descending neurons. $J$. Comp. Neurol. 219, 241-249.

Helfert, R.H, Bonneau, J.M., Wenthold, R.J. and Altschuler, R.A. (1989) GABA and glycine immunoreactivity in the guinea pig superior olivary complex. Brain Res. 501, 269286.

Itoh, K., Kamiya, H., Yasui, Y., Takada, M. and Mizuno, N. (1987) Direct projections from the dorsal column nuclei and the spinal trigeminal nuclei to the cochlear nuclei in the cat. Brain Res. 400, 145-150.

Juiz, J.M., Helfert, R.H., Wenthold, R.J., De Blas, A.L. and Altschuler, R.A. (1989) Immunocytochemical localization of the GABAa/benzodiazepine recrptor in the guinea pig cochlear mucleus: evidence for receptor localization heterogeneity. Brain Res. (in press).

Joseph, M.P., Guinan, Jr., J.J., Fullerton, B.C., Norris, B.E. and Kiang, N.Y.S. (1975) Number and distribution of stapedius motoneurons in cats. J. Comp. Neurol. 232, 4354.

Kane, E.S. (1977) Descending inputs to the octopus cell area of the cat cochlear nucleus: an electron microscopic study. $J$. Comp. Neurol. 2, 897-912.

Kane, E.S. and Conlee, J.W. (1979) Descending inputs to the caudal cochlear nucleus of the cat. Degeneration and autoradiographic studies. J. Comp. Neurol. 187, 759-784.
Kane, E.S. and Finn, R.C. (1979) Descending and intrinsic inputs to the dorsal cochlear nucleus of the cat. A horseradish peroxidase study. Neurosci. 2, 897-912.

Kiang, N.Y.S., Morest, D.K. and Godfrey, D.A. (1973) Stimulus coding at caudal levels of the cat's auditory system: Response chearacteristics of single units. In: Moller, A.R. (Ed.), Basic Mechanisms in Hearing. Academic Press, New York, London, pp. 455-478.

Mesulam, M.M. (1978) Tetramethyl benzidine for horseradish peroxidase neurochemistry: a non-carcinogenic blue reactionproduct with a superior sensitivity for visualizing neural afferents and efferents. J. Histochem. Cytochem. 26, 106117.

Morest, D.K. (1968) The collateral system of the medial nucleus of the trapezoid body of cat, its neuronal architecture, and relation to the olivocochlear bundle. Brain Res. 9, 288-311.

Oertel, D. (1983) Synaptic responses and electrical properties of cells in brain slices of the mouse anteroventral cochlear nucleus. J. Neurosci. 3, 2043-2053.

Oertel, D. (1984) Cells in the anteroventral cochlear nucleus are insensitive to $\mathrm{L}$-glutamate and L-aspartate: excitatory synaptic responses are not blocked by D-alpha-aminoadipate. Brain Res. 302, 213-220.

Osen, K.K. (1969) Cytoarchitecture of the cochlear nuclei in the cat. J. Comp. Neurol. 136, 453-484.

Osen, K.K., Mugnaini, E., Dahl, A.L. and Christiansen, A.L. (1984) Histochemical localization of acetylcholinesterase in the cochlear and superior olivary nuclei. A reappraisal with emphasis on the cochlear granule cell system. Arch. Ital. Biol. 122, 169-212.

Rall, W. (1977) Core conductor theory and cable properties of neurons. In: Kandel, E.R. (Ed.), Handbook of Physiology (Vol 1). Cellular Biology of Neurons. Waverly Press, Baltimore.

Ramon y Cajal, S. (1909) Histologie du Systeme Nerveux de lHomme et des Vertebres. Vol I. Inst. Ramon y Cajal, Madrid (1952 reprint), pp. 774-838.

Rasmussen, G.L. (1960) Ffferent fibers of the cochlear nerve and cochlear nucleus. In: G.L Rasmussen and W. Windle (Eds.), Neural mechanisms of the auditory and Vestibular Systcm. Springfield. IL: Charles C Thomas, pp 105-115.

Rasmussen, G.L. (1967) Efferent connections of the cochlear nucleus. In: A.B. Graham (Ed.), Sensorineural Hearing Processes and Disorders. J. and A. Churchill Ltd., London, pp. $61-75$

Robertson, D., Cole K.S. and Harvey, A.R. (1987) Brainstem organization of efferent projections to the guinea pig cochlea studied using the fluorescent tracers fast blue and diamidino yellow. Exp. Brain Res. 66, 449-457.

Ryan, A.F., Schwartz, I.R., Helfert, R.H., Keithley, E. and Wang. Z.X. (1987) Selective retrograde labeling of lateral olivocochlear neurons in the brainstem based on preferential uptake of 3 H-D-aspartic acid in the cochlea. J. Comp. Neurol 255, 606-616.

Spangler, K.M., Cant, N.B., Henkel, C.K.. Farley, G.R. and Warr, W.B. (1987) Descending projections from the superior olivary complex to the cochlear nucleus of the cat. J. Comp. Neurol. 259, 452-465.

Shore, S.E. and Nuttall A.L. (1985) High synchrony cochlear 
compound action potentials evoked by rising frequencyswept tone bursts, J. Acoust. Soc. Am. 78, 1286-1295.

Shore, S.E., Godfrey, D.A., Helfert, R.H., Bledsoe, S.C. and Altshuler R.A. (1991) The organization of pathways connecting the two cochlear nuclei in the guinea pig. Abstr. Assoc. Res. Otolaryngol,

Smith, R.L. and Brachman, M.L. (1980) Operating range and maximum response of single auditory nerve fibers. Brain Res. 184, 499-505.

Starr, A. and Wernick, J.S. (1968) Olivocochlear bundle: Effects on spontaneous and tone-evoked activities of single units in cat cochlear nucleus. J. Neurophysiol. 31, 549-564.

Strutz, J. and Beilenberg, K. (1983) Efferent acoustic neurons within the lateral superior olivary nucleus of the guinea pig. Brain Res. 299, 174-177.

Van Noort, J. (1969) The structure and connections of the inferior colliculus. Van Gorcum, N.V. The Netherlands.

Wenthold, R.J., Zempel, J.M., Parakkal, M.H., Reeks, K.A. and Altschuler, R.A. (1986) Immunocytochenical localiza- tion of GABA in the cochlear nucleus of the guinea pig. Brain Res. 380, 7-18.

Winslow, R.L. and Sachs, M.B. (1984) Effects of COCB stimulation on auditory-nerve fiber rate functions for tones in noise. Neurosci. Abstr. 10, 392.

Winter, I.M., Robertson, D. and Cole, K.S. (1989) Descending projections from auditory brainstem nuclei to the cochlea and cochlear nucleus of the guinea pig. J. Comp. Neurol 280, 143-157.

Young, E.D. and Brownell, W.E. (1986) Responses to tones and noise of single cells in dorsal cochlear nucleus of unanestheized cats. J. Neurophysiol. 39, 282-300.

Young, E.D. and Voight, H.F. (1981) The internal organization of the dorsal cochlear nucleus. In: J. Syka and L. Aitken (Eds.), Neuronal Mechanisms of Hearing, Plenum Press, New York, pp. 127-133.

Zook, J.M. (1985) The descending auditory pathway and the cochlear nucleus in the mustache bat. Soc. Neurosci. Abstr 11, 734 . 